\title{
Macrophage migration inhibitory factor is regulated by HIF-1a and cAMP and promotes renal cyst cell proliferation in a macrophage-independent manner
}

\author{
Wajima Safi $^{1,2} \cdot$ Andre Kraus $^{1} \cdot$ Steffen Grampp ${ }^{1} \cdot$ Johannes Schödel $^{1} \cdot$ Bjoern Buchholz $^{1}$ (i)
}

Received: 23 March 2020 / Revised: 10 August 2020 / Accepted: 12 August 2020 / Published online: 4 September 2020

(C) The Author(s) 2020

\begin{abstract}
Progressive cyst growth leads to decline of renal function in polycystic kidney disease. Macrophage migration inhibitory factor (MIF) was found to be upregulated in cyst-lining cells in a mouse model of polycystic kidney disease and to promote cyst growth. In addition, MIF can be secreted by tubular cells and may contribute to cyst growth in an autocrine manner. However, the underlying mechanisms leading to induction of MIF in cyst-lining cells remained elusive. Here, we demonstrate that hypoxiainducible transcription factor (HIF) $1 \alpha$ upregulates MIF in cyst-lining cells in a tubule-specific PKD1 knockout mouse. Pharmacological stabilization of HIF-1 $\alpha$ resulted in significant increase of MIF in cyst epithelial cells whereas tubule-specific knockout of HIF- $1 \alpha$ prevented MIF upregulation. Identical regulation could be found for ABCA1, which has been shown to act as a transport protein for MIF. Furthermore, we show that MIF and ABCA1 are direct target genes of HIF- $1 \alpha$ in human primary tubular cells. Next to HIF-1 $\alpha$ and hypoxia, we found MIF being additionally regulated by cAMP which is a strong promotor of cyst growth. In line with these findings, HIF- $1 \alpha$ - and cAMP-dependent in vitro cyst growth could be decreased by the MIFinhibitor ISO-1 which resulted in reduced cyst cell proliferation. In conclusion, HIF-1 $\alpha$ and cAMP regulate MIF in primary tubular cells and cyst-lining epithelial cells, and MIF promotes cyst growth in the absence of macrophages. In line with these findings, the MIF inhibitor ISO-1 attenuates HIF- $1 \alpha$ - and cAMP-dependent in vitro cyst enlargement.
\end{abstract}

\section{Key messages}

- MIF is upregulated in cyst-lining cells in a polycystic kidney disease mouse model.

- MIF upregulation is mediated by hypoxia-inducible transcription factor (HIF) $1 \alpha$.

- ABCA1, transport protein for MIF, is also regulated by HIF-1 $\alpha$ in vitro and in vivo.

- MIF is additionally regulated by cAMP, a strong promotor of cyst growth.

- MIF-inhibitor ISO-1 reduces HIF-1 $\alpha$ - and cAMP-dependent cyst growth.

Keywords Polycystic kidney disease $\cdot$ Macrophage migration inhibitory factor $\cdot$ Hypoxia-inducible factor $1 \alpha \cdot c$ AMP

Wajima Safi and Andre Kraus contributed equally to this work.

Electronic supplementary material The online version of this article (https://doi.org/10.1007/s00109-020-01964-1) contains supplementary material, which is available to authorized users.

Bjoern Buchholz

Bjoern.Buchholz@uk-erlangen.de

1 Department of Nephrology and Hypertension,

Friedrich-Alexander-University Erlangen-Nuernberg, Ulmenweg 18, D - 91054 Erlangen, Germany

2 Pluripotency for Organ Regeneration, Institute for Bioengineering of Catalonia (IBEC), The Barcelona Institute of Technology (BIST), Barcelona, Spain

\section{Introduction}

Autosomal dominant polycystic kidney disease (ADPKD) is the most common potentially lethal monogenic disorder affecting approximately 1:1000 [1]. ADPKD is mainly characterized by the development of fluid-filled cysts originating from tubular epithelial cells in both kidneys. Due to continuous cyst enlargement, adjacent intact nephrons become compressed which leads to decline of renal function and, depending on severity, consecutive need for renal replacement therapy [2]. ADPKD is caused by mutations in the PKD1- ( $\sim 85 \%$ of cases) or PKD2gene ( $\sim 15 \%$ of cases) [1]. Cyst growth and disease progression have been attributed to several mechanisms, including cyst cell 
proliferation, transepithelial fluid transport into the cysts' lumina, macrophage-dependent inflammation, and extracellular matrix deposition [3-6]. Cyst enlargement has been associated with interstitial inflammation reflected by macrophage infiltration resulting in decline of renal function [7, 8]. Inflammation may not only be a secondary event induced during the course of cyst expansion but may also actively contribute to cyst growth [9]. Thus macrophage depletion in an ADPKD mouse model resulted in smaller cysts, less cyst cell proliferation, and improved renal function $[7,8]$.

One of the pivotal regulators of innate immunity, the cytokine macrophage migration inhibitory factor (MIF), is an integral component of stress response that promotes proinflammatory functions of immune cells [10]. Recently, it has been shown that upregulation of MIF in cyst epithelial cells of an ADPKD mouse model resulted in increased cyst growth [9]. Data obtained from urinary bladder carcinoma cells, renal cancer cells, and in vitro renal tubule cells suggest that MIF may not only unfold its effects by signaling pathways that are induced by attracted macrophages but may also directly promote epithelial cell proliferation [9, 11, 12]. However, the mechanisms leading to induction of MIF in renal epithelial and cyst-lining cells as well as its transport into the extracellular milieu have remained elusive so far.

Continuous cyst enlargement leads to progressive tissue hypoxia which induces HIF- $1 \alpha$ in cyst epithelial cells [13-15]. HIF is a heterodimer consisting of a constitutively expressed $\beta$-subunit (HIF- $\beta$ ) and one of two alternative, oxygen-dependent $\alpha$-subunits (HIF-1 $\alpha$ and HIF-2 $\alpha$ ) which in the absence of oxygen accumulate and activate genes involved in metabolism, angiogenesis, immune reactions, and cell proliferation $[16,17]$. The continuous degradation of HIF- $\alpha$ by prolyl hydroxylase domain (PHD) enzymes in the presence of oxygen can be inhibited by prolyl-hydroxylase inhibitors which have been approved as erythropoiesis-stimulating agents [17-19]. However, recently, we have shown that stimulation of HIF-1 $\alpha$ (the isoform present in tubular and cyst-lining cells) may be detrimental by significantly promoting cyst growth in an ADPKD mouse model [15]. HIF-1 $\alpha$ promoted calciumactivated chloride secretion but was also associated with increased cyst cell proliferation, especially in a rapid progressive ADPKD mouse model $[14,15]$. Since cyst expansion aggravates regional hypoxia which then induces $\operatorname{HIF}-1 \alpha$, a feedforward loop is established that accelerates cyst expansion and disease progression [20]. MIF has been shown to be upregulated by hypoxia in different tumors [21, 22]. In addition, MIF has been identified as a HIF target gene in cells of the trachea, lungs, and in cancer cells [23-26]. A validation of this finding in the context of renal tissue and cysts is lacking. In addition, in vivo MIF-mediated cyst growth has been referred to macrophage recruitment and the release of monocyte chemotactic protein 1 (MCP-1) and inflammatory cytokine TNF- $\alpha$ [9]. However, in vitro MIF may affect proliferation of renal tubule cells and renal clear cell carcinoma cells independent from the presence of macrophages $[12,27]$. Therefore, we wondered if secreted MIF may increase cyst growth in an autocrine/paracrine way. Of note, MIF secretion by immune and epithelial cells occurs apically by a nonclassical export route involving ABCA1 transporter [28].

Here, we provide data showing that (i) MIF as well as its transporter protein $\mathrm{ABCA} 1$ are regulated by $\mathrm{HIF}-1 \alpha$ in cystlining cells in vivo and in vitro, (ii) that cAMP is also a regulator of MIF, and (iii) MIF induces cyst cell proliferation in vitro in a macrophage-independent way which can be inhibited by the MIF-inhibitor ISO-1.

\section{Results}

\section{HIF-1a stabilization leads to an increase in MIF and $A B C A 1$ expression in cyst-lining cells in vivo}

In order to investigate whether there is evidence for HIF- $1 \alpha$ mediated MIF-expression in vivo, we used an inducible, kidney-epithelium-specific PKD1 knockout mouse model $\left(\mathrm{KspCreER} R^{\mathrm{T} 2} ; P k d 1^{\text {lox;lox }}\right)$ and crossed it with floxed HIF-1 $\alpha$ mice $\left(H i f-1 \alpha^{\text {lox;lox }}\right)$ to obtain an inducible tubule-specific deletion of PKD1 and HIF-1 $\alpha$ in renal tubular cells. Tubular deletion of PKD1 was induced at postnatal days 35-37 which resulted in a slowly progressing polycystic renal phenotype which did not result in hypoxia or consecutive induction of HIF- $1 \alpha$ as shown previously [15]. However, tubular HIF-1 $\alpha$ was significantly induced by treatment with the prolylhydroxylase-inhibitor 2-(1-chloro-4-hydroxy-isoquinoline-3carboxamido) acetate (ICA) $[15,29]$. Induction of HIF-1 $\alpha$ by ICA resulted in a significant cyst progression which could be rescued by tubular deletion of HIF-1 $\alpha$ as shown previously $[15,30]$. We tested renal cysts within kidney tissue obtained from the named mouse model for ICA- and HIF-1 $\alpha$ dependent effects on MIF as well as ABCA1 expression by immunohistochemistry. We found a strong induction of MIF by ICA in $\mathrm{KspCreER} R^{\mathrm{T} 2} ; P k d 1^{\text {lox;lox }}$ kidneys which was significantly reduced in animals with an additional deletion of tubular HIF-1 $\alpha$ (Fig. 1a and Supplemental Figure 1A). ICA also increased MIF expression in wildtype kidneys pointing towards HIF-mediated induction irrespective of the genetic background (Supplemental Figure 2A). In addition, ABCA1 showed a concordant pattern of expression in cysts obtained from the named mouse models (Fig. 1b and Supplemental Figures 1B and 2B). Accordingly, ABCA1 expression was significantly higher in $\mathrm{KspCreER}{ }^{\mathrm{T} 2} ; P k d 1^{\text {lox;lox }}$ kidneys upon treatment with ICA whereas expression was significantly reduced in $\mathrm{KspCreER}{ }^{\mathrm{T} 2} ; P k d 1^{\text {lox;lox }} ; \mathrm{Hif}-1 \alpha^{\text {lox/lox }}$ mice treated with ICA. MIF expression did not only increase in overall levels but also showed different subcellular patterns which correlated with the degree of cyst formation and expansion. 
While MIF showed a predominant nuclear pattern in normal and mildly dilated tubules, it showed a switch towards a cytoplasmic localization in cysts (Supplemental Figures 3 and 4). Previous findings suggested that MIF secretion is mediated by ABCA1 [28]. This is further supported by our findings showing coexpression of MIF and ABCA1 in cyst-lining cells (Supplemental Figure 4) and correlating numbers of MIF- and ABCA1-positive cysts in kidneys with different genetic backgrounds and upon treatment with ICA (Supplemental Figure 5). In addition, protein expression of MIF was not restricted to specific tubule-segments but rather correlated with coexpression of HIF-1 $\alpha$ (Supplemental Figure 6). These data suggest a HIF-1 $\alpha$-dependent regulation of MIF and ABCA1 in cyst epithelial cells in vivo.

\section{MIF and ABCA1 are target genes of HIF-1a in human renal epithelial cells}

Next, we aimed to evaluate HIF- $1 \alpha$-dependent regulation of MIF and ABCA1 in human primary renal tubular epithelial cells (hPTECs). HPTECs were isolated from healthy parts of the kidneys of patients who were nephrectomized because of kidney cancer [3 1]. HIF stabilization by dimethyloxalylglycine (DMOG) in hPTECs resulted in increased MIF and ABCA1 mRNA expression (Fig. 2a). To assess the direct involvement of HIF-1 $\alpha$ in transcriptional activation of these genes, we interrogated available nextgeneration sequencing data sets from HIF chromatin immunoprecipitation (ChIP-seq) experiments in hPTECs [32]. We observed HIF DNA-binding (HIF-1 $\alpha$ and HIF-1 $\beta$ ) at the promoter region of the $\mathrm{MIF}$ gene and at two regions at the ABCA1 locus (Fig. 2b). To confirm involvement of HIF in regulation of MIF and ABCA1 expression, we performed knockdown of HIF-1 $\alpha$ and its dimerization partner HIF-1ß in the primary cells (Fig. 2c). Knockdown of either subunit led to a reduced induction of MIF, ABCA1, and the wellcharacterized HIF- $1 \alpha$ target gene EGLN3, which served as control (Fig. 2c). Knockdown of HIF-1 $\alpha$ and HIF-1 $\beta$ was also confirmed on protein level (Supplemental Figure 7). In summary, these data show that MIF and ABCA1 are direct transcriptional targets of $\mathrm{HIF}-1 \alpha$ in human primary renal tubular cells.

\section{MIF is expressed in pIMDCK cysts and upregulated by ICA, hypoxia and forskolin}

We have previously established an in vitro cyst model by the use of a subclone of Madin-Darby canine kidney cells which highly resemble principal cells of the collecting duct (principal-like (pl) MDCK cells) - the main origin of cyst development in ADPKD [33, 34]. plMDCK cells form cysts within a collagen I matrix and grow in a secretion-dependent manner sharing many characteristics with ADPKD cyst-lining cells
$[33,35,36]$. plMDCK cells were either exposed to hypoxia $\left(5 \% \mathrm{O}_{2}\right)$ or ICA $(10 \mu \mathrm{M})$ for $24 \mathrm{~h}$ to stabilize HIF. We then tested plMDCK cells for MIF protein expression by the use of western blot and could detect a significant upregulation of MIF upon hypoxia and ICA (Fig. 3a and b). Since cyst growth in this model depends on cAMP according to the situation in vivo [4, 33, 37], we next treated the cells additionally with forskolin (FSK; $10 \mu \mathrm{M}$ ) for $24 \mathrm{~h}$ to test for cAMP-dependent effects on MIF expression. Forskolin resulted in a significant increase of MIF protein expression which could be additionally augmented by ICA (Fig. 3c, d) suggesting both, HIF-1 $\alpha$ and cAMP as regulators of MIF.

\section{MIF inhibitor ISO-1 inhibits cyst growth in a dose- dependent manner}

In order to test if MIF may directly affect cyst growth (independent of macrophage recruitment), we tested for effects of recombinant MIF-protein (rMIF) at concentrations of $10 \mathrm{ng} / \mathrm{ml}$ and $100 \mathrm{ng} / \mathrm{ml}$ in our plMDCK cyst model but we did not find any significant effect on in vitro cyst growth (not shown). Of note, rMIF can only be applied from the basolateral site in the 3D cyst model. Next, we tested the cell permeable MIFinhibitor 4,5-dihydro-3-(4-hydroxyphenyl)-5-isoxazoleacetic acid methyl ester (ISO-1) in our plMDCK cyst model. ISO-1 significantly inhibited cAMP-dependent cyst enlargement in a dose-dependent manner (Fig. 4). ICA resulted in an increase of cyst growth as shown previously $[14,15]$ which could also be attenuated by ISO-1 in a dose-dependent manner (Fig. 4). These data indicate, that inhibition of MIF reduces cAMPand HIF-1 $\alpha$-dependent in vitro cyst enlargement.

\section{MIF-inhibitor ISO-1 inhibits and rMIF increases pIMDCK cell proliferation}

Next, we wanted to test if ISO-1-dependent decrease of cyst growth can be referred to reduction in cell proliferation. In addition, we wondered if apical application of rMIF (at the site of secretion in vivo) may affect cyst cell proliferation whereas basal application as done in the in vitro cyst assays may be ineffective. Therefore, MTS assays were performed in plMDCK cells grown in the presence and absence of rMIF and ISO- 1 for $48 \mathrm{~h}$ showing significant reduction of cell number in the presence of ISO-1 and significantly increased cell number in the presence of rMIF (Fig. 5a). In order to verify these results and to exclude artifacts caused by potential differences in initial cell adhesion after seeding of the cells, we used another cell proliferation assay, and all cells were grown in the same control medium for $24 \mathrm{~h}$. Then medium was changed, and cells were treated with ISO-1 or rMIF for $24 \mathrm{~h}$. Thereafter, the increase of cell number from time point 48 to $58 \mathrm{~h}$ was measured at the different conditions. In concordance with the results above, ISO-1 reduced, whereas 
a
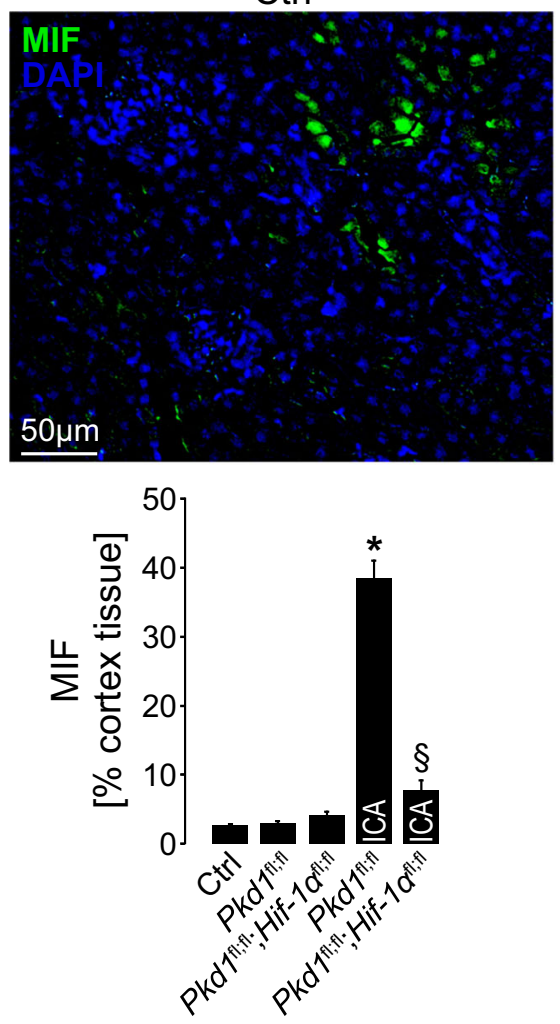

b
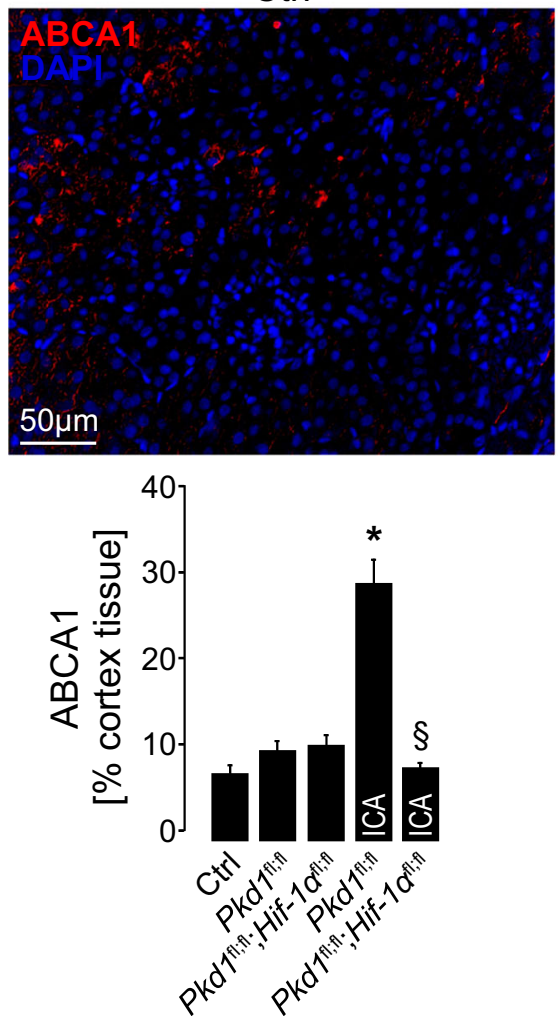

$P k d 1^{\mathrm{fl} ; \mathrm{fl}}$
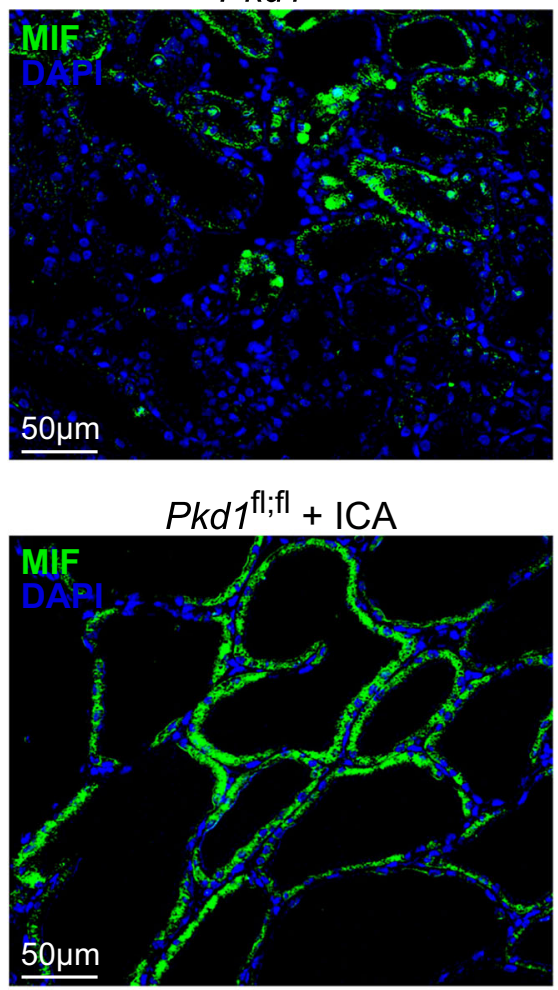

$P k d 1^{\mathrm{fl} ; \mathrm{fl}}$
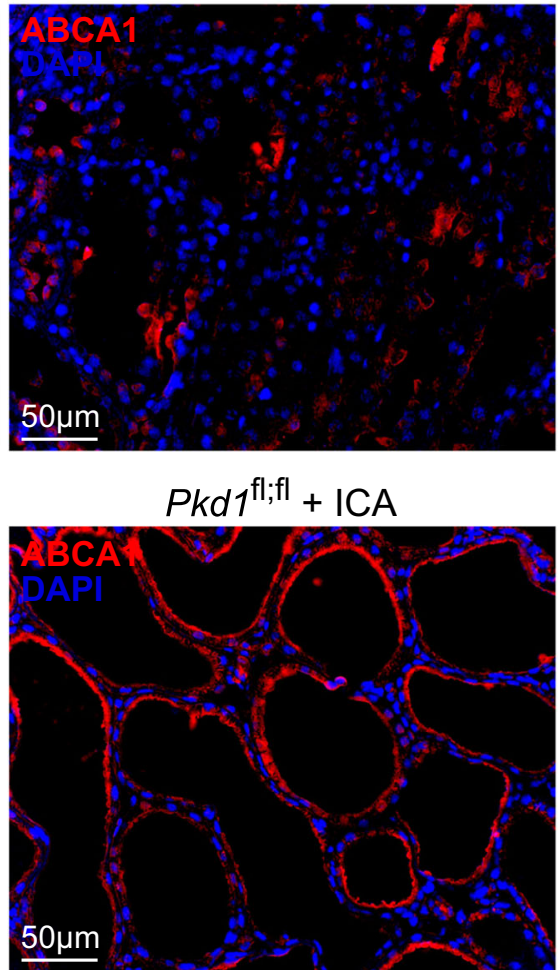

$50 \mu \mathrm{m}$

$50 \mu \mathrm{m}$

$P k d 1^{\mathrm{fl} ; \mathrm{fl}} ; H i f-1 \alpha^{\mathrm{fl} ; \mathrm{fl}}$

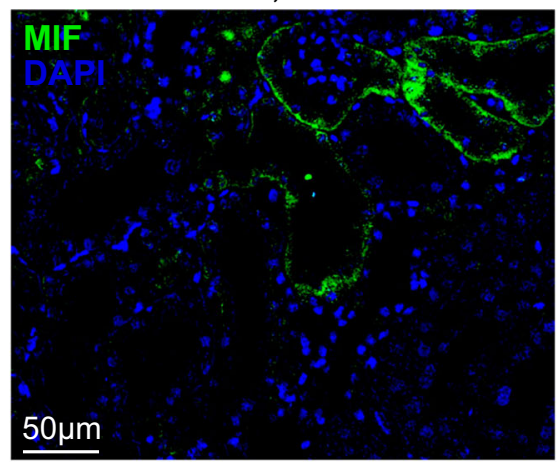

$P k d 1^{\mathrm{fl} ; \mathrm{fl} ;}, H i f-1 \alpha^{\mathrm{fl} ; \mathrm{fl}}+\mathrm{ICA}$

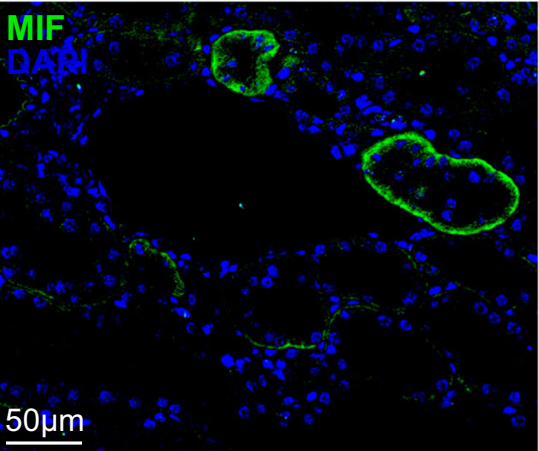

$P k d 1^{\mathrm{fl} ; \mathrm{fl}} ; H i f-1 \alpha^{\mathrm{fl} ; \mathrm{fl}}$

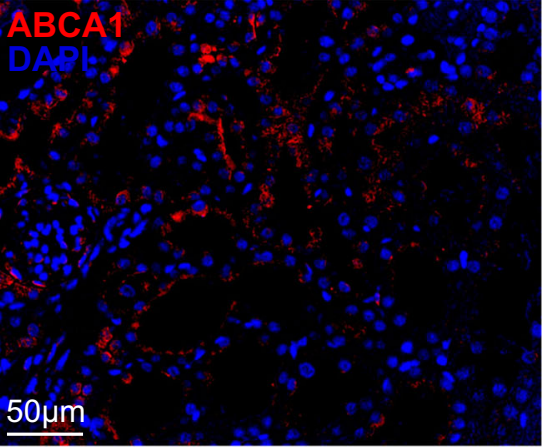

$P k d 1^{f l ;} ; \mathrm{fl} ; H i f-1 \alpha^{f l ; f l}+I C A$

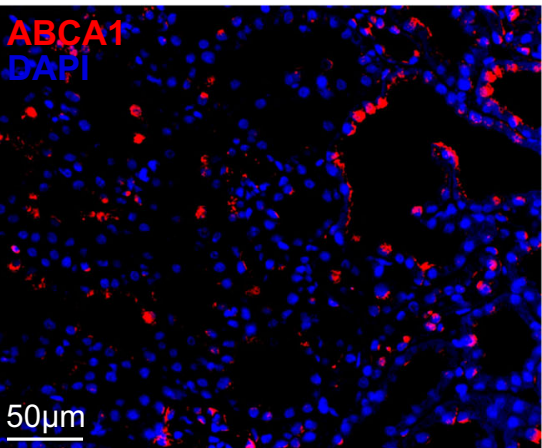


Fig. 1 MIF and ABCA1 are expressed in a HIF- $1 \alpha$-dependent manner in cyst-lining cells of an ADPKD mouse model. Tamoxifen was applied at postnatal days 35-37 to induce tubule-specific deletion of PKD1 in $\mathrm{KspCreER}{ }^{\mathrm{T} 2} ; P k d 1^{\text {lox;lox }}\left(P k d 1^{\mathrm{fl} ; \mathrm{fl}} ; n=7\right)$ mice. In parallel, genetic deletion was induced in $\mathrm{KspCreER}{ }^{\mathrm{T} 2} ; P k d 1^{\text {lox;lox}} ; \mathrm{Hif}-1 \alpha^{\text {lox/lox }}\left(P k d 1^{\mathrm{fl} ; \mathrm{fl}} ;\right.$ Hif$\left.1 \alpha^{\mathrm{fl} ; \mathrm{fl}} ; n=5\right)$ mice to receive tubular codeletion of PKD1 and HIF-1 $\alpha$. Mice were then either treated with the prolylhydroxylase inhibitor 2-(1chloro-4-hydroxyisoquinoline-3-carboxamido) acetate $\left(P k d 1^{\mathrm{fl} ; \mathrm{fl}}+\mathrm{ICA}\right.$; $n=6) ;\left(P k d 1^{\mathrm{fl} ; \mathrm{fl}} ;\right.$ Hif- $\left.1 \alpha^{\mathrm{fl} ; \mathrm{fl}}+\mathrm{ICA} ; n=6\right)$ or its vehicle for 12 weeks. Noninduced mice served as controls ( $\mathrm{Ctrl} ; n=4)$. a As shown previously, the abovementioned ADPKD mouse model $\left(P k d 1^{\mathrm{fl} ; \mathrm{fl}}\right)$ shows a mild progression which does not lead to hypoxia or induction of HIF-1 $\alpha$. In line with these findings, MIF expression did not differ in the cortex between $\mathrm{Ctrl}, P k d 1^{\mathrm{fl} ; \mathrm{fl}}$, and $P k d 1^{\mathrm{fl} ; \mathrm{fl}} ; H i f-1 \alpha^{\mathrm{fl} ; \mathrm{fl}}$ kidneys. However, application of ICA $\left(P k d 1^{\mathrm{fl} ; \mathrm{fl}}+\mathrm{ICA}\right)$ resulted in a significant increase of HIF-1 $\alpha$ shown previously which was prevented in mice co-deleted for HIF-1 $\alpha$ $\left(P k d 1^{\mathrm{fl} ; \mathrm{fl}} ; H i f-1 \alpha^{\mathrm{fl} ; \mathrm{fl}}+\mathrm{ICA}\right)$. In line with the assumption of MIF being regulated by HIF- $1 \alpha$, MIF expression was significantly increased in the cortex of $P k d 1^{\mathrm{fl} ; \mathrm{fl}}+\mathrm{ICA}$ mice which could be prevented in mice

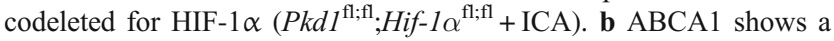
comparable pattern of HIF-dependent expression as MIF in cyst cells in the renal cortex of the chosen models. *Significant compared with Ctrl. $\S$ Significant compared with $P k d 1^{\mathrm{fl} ; \mathrm{fl}}+\mathrm{ICA}$

rMIF increased cell numbers (Fig. 5b). These data suggest that MIF promotes pIMDCK cell proliferation.

\section{ISO-1 leads to a reduction of the cell proliferation marker proliferating cell nuclear antigen in pIMDCK cysts}

Since MIF promoted plMDCK cell proliferation in vitro, we next tested for proliferation markers in our plMDCK cyst model. Therefore, we stained the cysts for MIF and the cell proliferation marker proliferating cell nuclear antigen (PCNA) and found a correlation of both. Application of ICA was associated with an increase in MIF expression which was associated with an increase in PCNA (Fig. 6). In contrast, ISO-1 significantly reduced both, expression of MIF and PCNA (Fig. 6), suggesting that MIF-dependent cyst enlargement is due to increased cyst cell proliferation. Next to proliferation, apoptosis has also been shown to affect cyst growth [38]. Therefore, we performed TUNEL assays in our cyst model and found a reduction of apoptosis by application of ISO-1, whereas ICA led to an increased apoptosis rate (Supplemental Figure 8). These data indicate that MIF may affect apoptosis of cyst epithelial cells.

\section{Discussion}

Continuous cyst expansion and subsequent compression of primarily unaffected kidney tissue is considered as the main driving force for the decline in renal function in ADPKD [2]. Therefore, identifying mechanisms of cyst growth is crucial for developing strategies to retard cyst growth and preserve renal function. Cyst growth is supposed to be mediated by at least three main forces: cyst cell proliferation, influx of fluid, and inflammation [1]. Clinical studies have been conducted targeting cyst cell proliferation by inhibition of mTOR or transepithelial cyst secretion by pharmacological inhibition of the vasopressin 2 receptor (V2R) [39-41]. These strategies were either not successful or showed quantitatively modest effects with relevant side effects [40, 41]. Thus, unravelling relevant pathways contributing to cyst growth in order to find druggable targets is of significant clinical interest.

We have previously shown that cyst growth is accompanied by regional hypoxia, which induces HIF-1 $\alpha$ in cystlining cells which then promotes cyst growth primarily through induction of genes that mediate calcium-activated chloride secretion [13-15]. However, we also found HIF$1 \alpha$-dependent increase of cyst cell proliferation in vivo, which was especially pronounced in a rapid progressive ADPKD mouse model [15]. The mechanisms, however, remained elusive. MIF has previously been described to be transcriptionally regulated by HIF-1 $\alpha$ in cells of the trachea, lung and in cancer cells [22, 24, 26, 42, 43]. In addition, MIF has been shown to be upregulated and promote cyst growth in an ADPKD mouse model [9]. Our data demonstrate that MIF upregulation can be explained to some extent by HIF-1 $\alpha$ dependent transcriptional regulation in vivo and in vitro. The ChIP-seq signals from primary tubular cells derived in our study precisely overlap with the previously postulated HRE within the 5' UTR of the MIF gene [24]. We therefore conclude that the functional element mediating HIF-binding in tubular cells is identical to the previously described one. Next to HIF-1 $\alpha$, we also found cAMP which is a main driver of cyst growth in ADPKD as an additional regulator of MIF expression. In line with these findings, MIF has recently been reported to be transcriptionally regulated by cAMP response element-binding protein (CREB) in immune and epithelial cells [44]. However, if cAMP-dependent upregulation of MIF can be referred to CREB in cyst epithelial cells has to be further analyzed in the future. Interestingly, HIF-1 $\alpha$ and cAMP showed synergistic upregulation of MIF in cystforming cells. If this can be referred to different mechanisms of MIF regulation or if HIF- $1 \alpha$ and cAMP merge into, a common pathway remains elusive at the moment.

HIF-1 $\alpha$ stabilization by the prolyl-hydroxylase inhibitor ICA did not only result in an increase of MIF protein in cyst-lining cells but also induced cyst growth which could be inhibited by the MIF-inhibitor ISO-1. Therefore, these findings indicate that HIF- $1 \alpha$-mediated cyst cell proliferation could be in parts mediated by MIF. In addition, we also found a reduction in apoptosis in plMDCK cysts upon application of ISO-1 which is in line with a recent report that showed that mice lacking MIF had less apoptosis in acute kidney injury upon application of cisplatin [45]. In PKD, the role of apoptosis is still a matter of debate. While inhibition of apoptosis has 
a

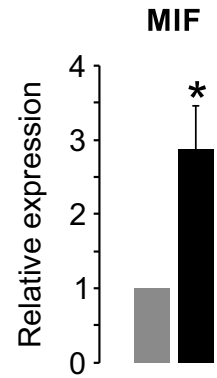

ABCA1

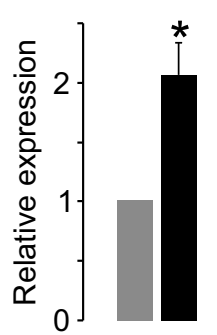

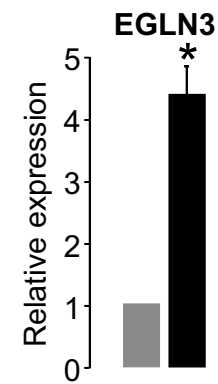

- Control
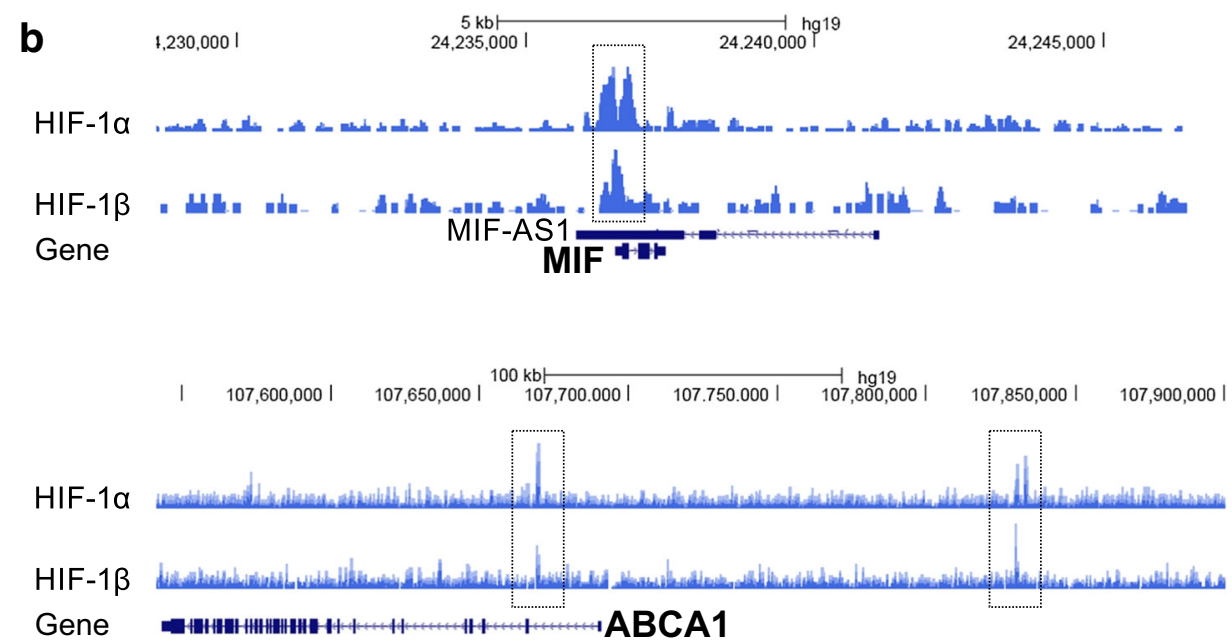

C

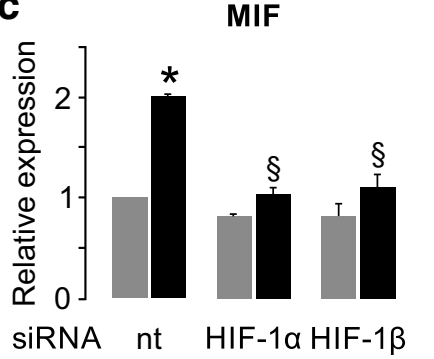

ABCA1

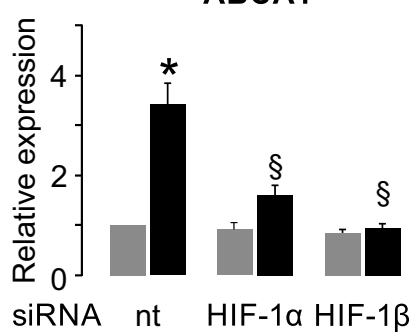

EGLN3

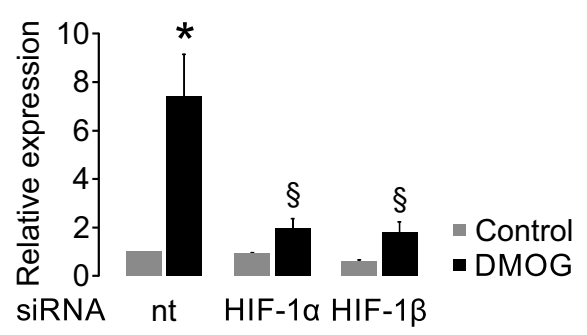

Fig. $2 \mathrm{MIF}$ and ABCA1 are HIF- $1 \alpha$ target genes in human primary tubular epithelial cells (hPTECs). a HIF stabilization by DMOG in $\mathrm{hPTCs}$ for $16 \mathrm{~h}$ led to a significantly increased expression of MIF and ABCA 1 mRNA ( $n=13$ for MIF, $n=8$ for ABCA1, and $n=6$ for EGLN3, egl nine homolog 3) compared with vehicle control. The known HIF-1 $\alpha$ target gene EGLN3 served as positive control. b HIF- $1 \alpha$ - and HIF-1 $\beta$ ChIP-seq signals at the genomic regions coding for MIF or ABCA1, respectively, reveal HIF DNA interactions at the promoter of MIF and at two regions at the ABCA1 locus (dotted rectangles) in hPTCs.

been shown to delay renal cyst growth in some animal models of PKD, induction of apoptosis of cyst-lining epithelial cells has been shown to slow disease progression in Pkd1 knockout mice [46]. However, our results are in conflict with data showing an induction of apoptosis upon treatment with ISO-1 in an ADPKD mouse model [9]. Therefore, the exact role of MIF for apoptosis, and also potentially autophagy, and its contribution to cyst growth in ADPKD needs further investigation.
MIF-AS1: MIF antisense 1 which is encoded close to MIF in the indicated genomic interval of the human genome. $\mathbf{c}$ Expression qPCR of MIF and $\mathrm{ABCA} 1$, respectively, in HIF- $1 \alpha$ and HIF- $1 \beta$ siRNA depleted hPTCs with or without DMOG treatment for $16 \mathrm{~h}$. MIF or ABCA1 mRNA levels increased in DMOG-treated cells and are significantly reduced in HIF-depleted cells. EGLN3 served as positive control $(n=3$ individual experiments). *Significant compared with vehicle control. §Significant compared with cells treated with nontargeting (nt) siRNA

Interestingly, although ICA also results in increased expression of MIF in wildtype kidneys, it does not result in cyst formation [47] (and Supplemental Figure 2). This confirms previous findings that HIF is not involved in early cyst formation but rather promotes cyst enlargement in advanced stages of PKD $[15,30]$.

Since MIF has been shown to be secreted [9], we tested for HIF-dependent regulation of $\mathrm{ABCA} 1$, a putative 


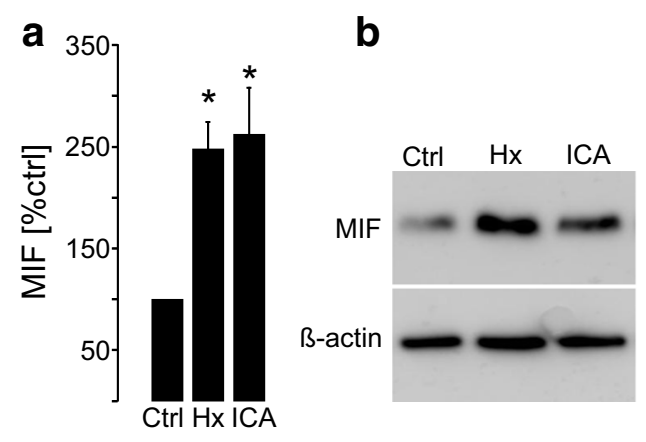

Fig. 3 MIF is regulated by HIF- $1 \alpha$ and cAMP in cyst-forming plMDCK cells. A Analysis of MIF protein expression normalized to $\beta$-actin in plMDCK cells by Western blot under control condition (Ctrl), in the presence of hypoxia $\left(5 \% \mathrm{O}_{2} ; \mathrm{Hx}\right)$ or stimulated with $10 \mu \mathrm{M}$ ICA $(\mathrm{n}=4$ individual experiments). B Representative Western blot. C Analysis of MIF protein expression normalized to $\beta$-actin in plMDCK cells by

transporter protein of MIF [28]. In line with the hypothesis, that hypoxia triggers both, MIF expression and the induction of the MIF transporter ABCA1; we found that expression of ABCA1 is directly transactivated by HIF$1 \alpha$. Therefore, HIF- $1 \alpha$ could not only increase MIF expression but also directly affect MIF secretion via increased levels of ABCA1. However, although highly intuitive, further analyses will be needed to reliably confirm the transport function of ABCA1 for MIF in renal cells.

MIF has been shown to recruit macrophages by induction of monocyte chemotactic protein 1 (MCP-1) and induce proinflammatory pathways through, amongst others, tumor necrosis factor (TNF)- $\alpha$. TNF- $\alpha$ may also promote cyst cell proliferation $[48,49]$. Therefore, MIF-dependent cyst enlargement may either be driven indirectly via attracted macrophages or in a direct way. MIF may be capable of inducing

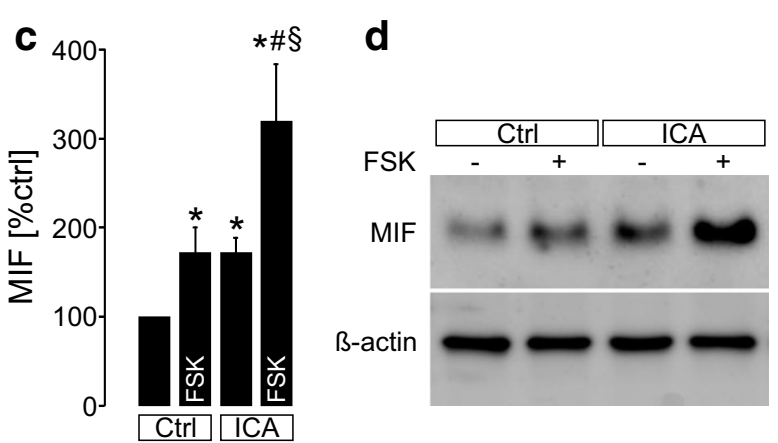

Western blot under control condition $(\mathrm{Ctrl}) \pm$ forskolin $(\mathrm{FSK} ; 10 \mu \mathrm{M})$ or stimulated with $10 \mu \mathrm{M}$ ICA \pm forskolin (FSK; $10 \mu \mathrm{M})(\mathrm{n}=7$ individual experiments). D Representative Western blot. * significant compared to Ctrl (-FSK). § significant compared to ICA (-FSK). \# significant compared to $\mathrm{Ctrl}(+\mathrm{FSK})$.

cell proliferation by its increase in the cytosol as well as by extracellular application. Here, we show that extracellular application of rMIF increased cell proliferation. However, whether intracellular or extracellular expression of MIF is the dominant driver for cell proliferation (in the absence of macrophages) has to be further evaluated. Nevertheless, our data from the in vitro cyst model suggest that MIF mediates cyst growth not only by recruitment of macrophages but also in a direct manner. rMIF promoted cell proliferation in $2 \mathrm{D}$ cell cultures but did not affect in vitro $3 \mathrm{D}$ cyst growth. This may be explained by apical secretion of MIF into the cysts' lumen [9] which suggests that MIF most likely acts from the cell's apical site. This is in line with the observed increase of the MIF receptor $\mathrm{CD} 74$ and an indicated apical staining of CD74 in ADPKD cysts [9]. In the cyst model, however, rMIF can only be applied from the basolateral site. In contrast, ISO-1 is a cell-

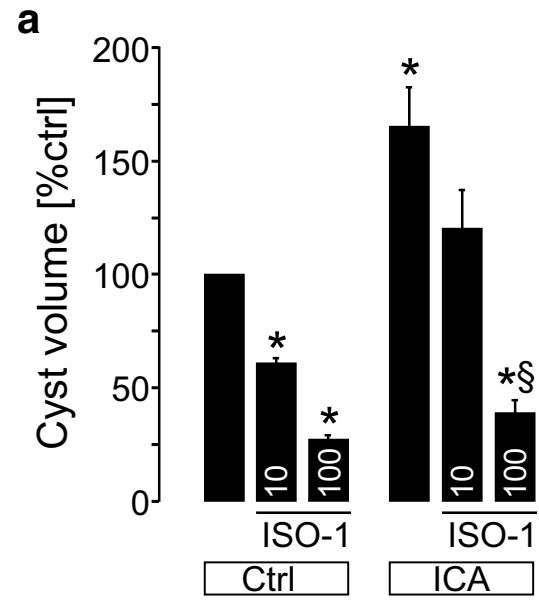

Fig. 4 Inhibition of MIF reduces in vitro cyst growth in a dose-dependent manner and prevents ICA-dependent cyst enlargement. a plMDCK cells forming cysts within a collagen I matrix were exposed to control medium containing forskolin $(10 \mu \mathrm{M}) \pm$ application of the MIF-inhibitor ISO-1 $(10 \mu \mathrm{M}$ and $100 \mu \mathrm{M})$ and \pm application of ICA $(10 \mu \mathrm{M})$. Graph shows

b

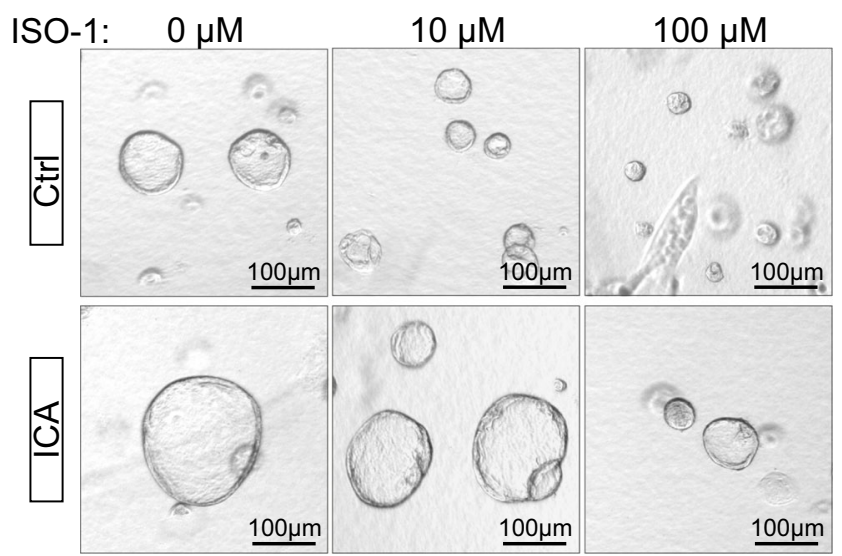

mean cyst sizes after 5 days of treatment from three individual experiments comprising the analysis of 210-240 cysts per condition (control (absence of ISO-1) volume was set $=100 \%$ ). b Representative cysts within the collagen matrix at day 5. *Significant compared with $\mathrm{Ctrl}$. §Significant compared with ICA 


\section{a}
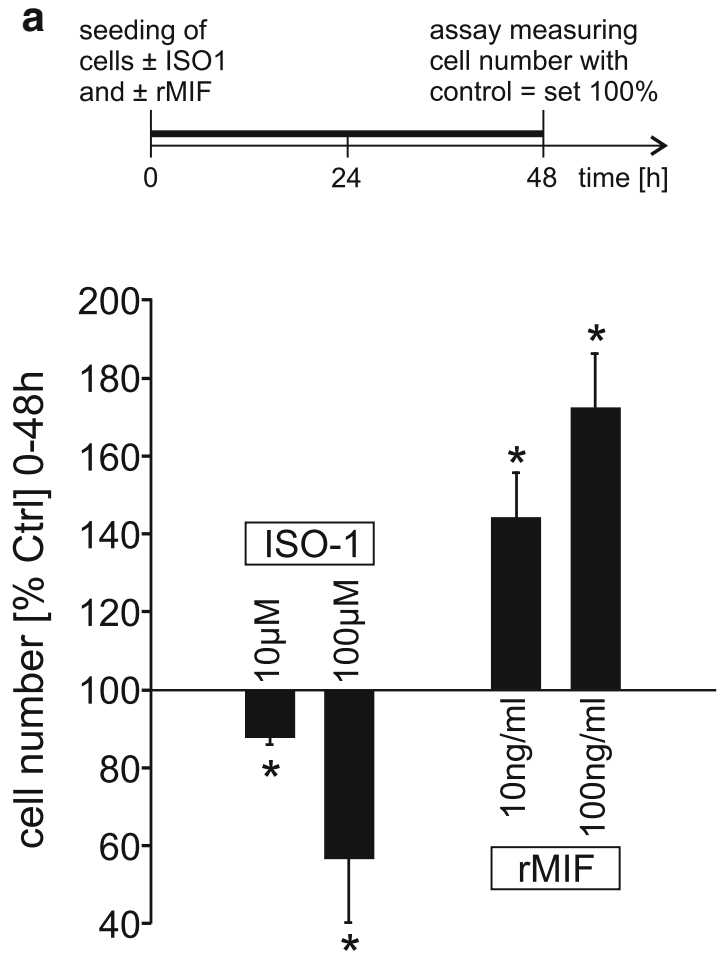

Fig. 5 MIF promotes plMDCK cell proliferation. a plMDCK cells were seeded in 96 wells and grown in the presence and absence of rMIF (10 and $100 \mathrm{ng} / \mathrm{ml}$ ) and ISO-1 (10 and $100 \mu \mathrm{M})$ for $48 \mathrm{~h}$. Thereafter, a MTS assay was performed. Graph shows means of the obtained luminescence which correlates with the number of viable cells from $n=6$ individual experiments and was normalized to control treated cells set $=100 \%$. b plMDCK cells were seeded in 96 wells and grown in the presence of

permeable isoxazoline compound, which therefore can act from both sites.

MIF is regulated by HIF- $1 \alpha$ as well as cAMP, both of which have been shown to promote cyst enlargement in PKD. In addition, MIF secretion may also be affected by HIF- $1 \alpha$ since the MIF transporter ABCA1 is also transcriptionally regulated by HIF- $1 \alpha$. Therefore, MIF could qualify as a druggable target downstream of HIF- $1 \alpha$ and cAMP in order to reduce cyst enlargement and preserve renal function.

\section{Methods}

\section{pIMDCK cyst model}

In vitro cyst assays were performed as described previously [50]. Principal-like Madin-Darby canine kidney (plMDCK) cells initially described as $\mathrm{C} 7$ cell clones by Gekle et al. [51] were a kind gift of Hans Oberleithner, University of Muenster as described previously [33]. plMDCK cells were resuspended as single-cell suspensions in a type I collagen matrix in 24well plates (3-6 wells per condition) in presence of $37^{\circ} \mathrm{C}$ and
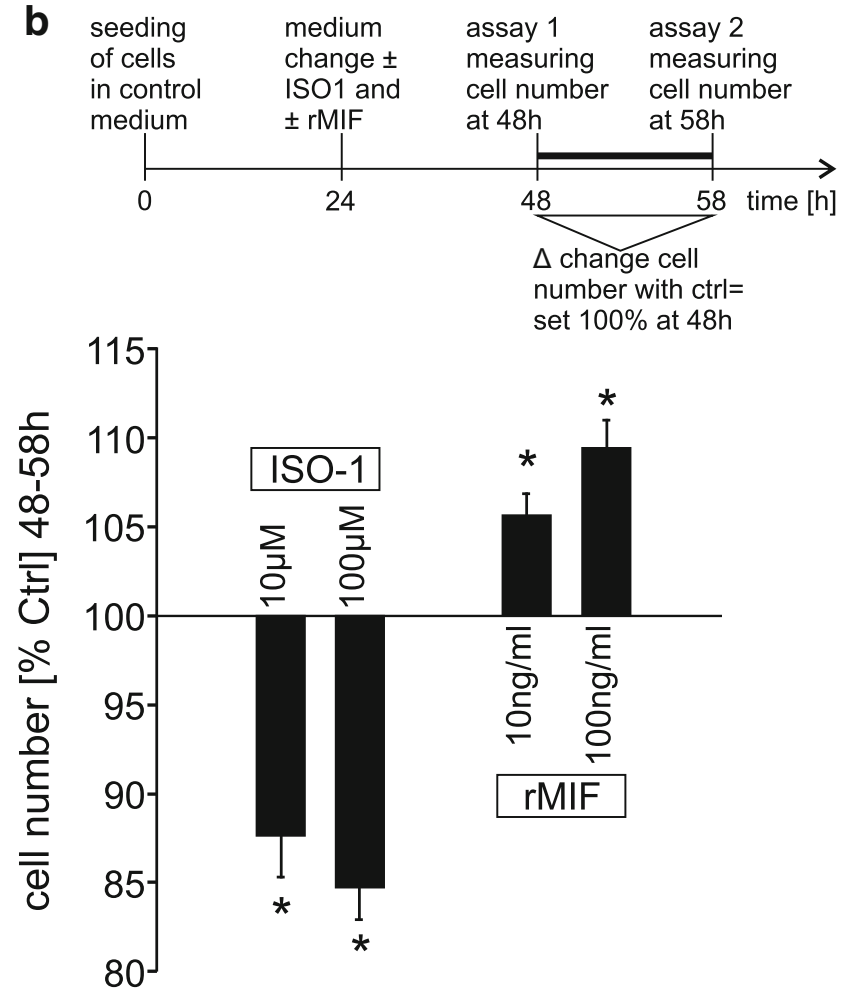

control medium for $24 \mathrm{~h}$. Then, medium was changed and supplemented with the cell viability substrate, NanoLuc Enzyme and treated with ISO-1 $(10$ and $100 \mu \mathrm{M})$ or rMIF (10 and $100 \mathrm{ng} / \mathrm{ml})$ for $24 \mathrm{~h}$. Thereafter, the increase in luminescence from time point 48 to $58 \mathrm{~h}$ was measured. Graph shows the deviation of luminescence signal compared to control cells set $=100 \%$ in $n=6$ individual experiments. *Significant compared with control

$21 \% \mathrm{O}_{2} / 5 \% \mathrm{CO}_{2}$ in modified MEM containing Earl's balanced salt solution supplemented with $2 \mathrm{mM}$ L-glutamine, $10 \%$ heat-inactivated $\mathrm{FCS}, 50 \mathrm{IU} / \mathrm{ml}$ penicillin, and $50 \mu \mathrm{g} / \mathrm{ml}$ streptomycin. Forskolin (Sigma-Aldrich), 2-(1chloro-4-hydroxyisoquinoline-3-carboxamido) acetate (ICA) [29], and ISO-1 (Calbiochem, San Diego, USA) were added to the medium at day 0 and changed every 2 days. Experimental conditions were performed in the presence of forskolin. After 5 days, four random visual fields per well were photographed with a Zeiss Primo Vert microscope and a Zeiss Axiocam 105 color camera (both Zeiss Microscopy $\mathrm{GmbH}$, Jena, Germany). Cyst diameters of all captured cysts that were nearly spherical were measured with ImageJ (V. 1.48) and the use of a Wacom Tablet device. Cyst volume was then estimated using the formula for the volume of a sphere, $4 / 3 \pi r^{3}$.

\section{ChIP-seq data}

Data from HIF ChIP-seq experiments in human primary tubular cells were generated in previous work (GEO data set: GSE101064, sample GSM2698833 for HIF-1 $\alpha$, and sample 

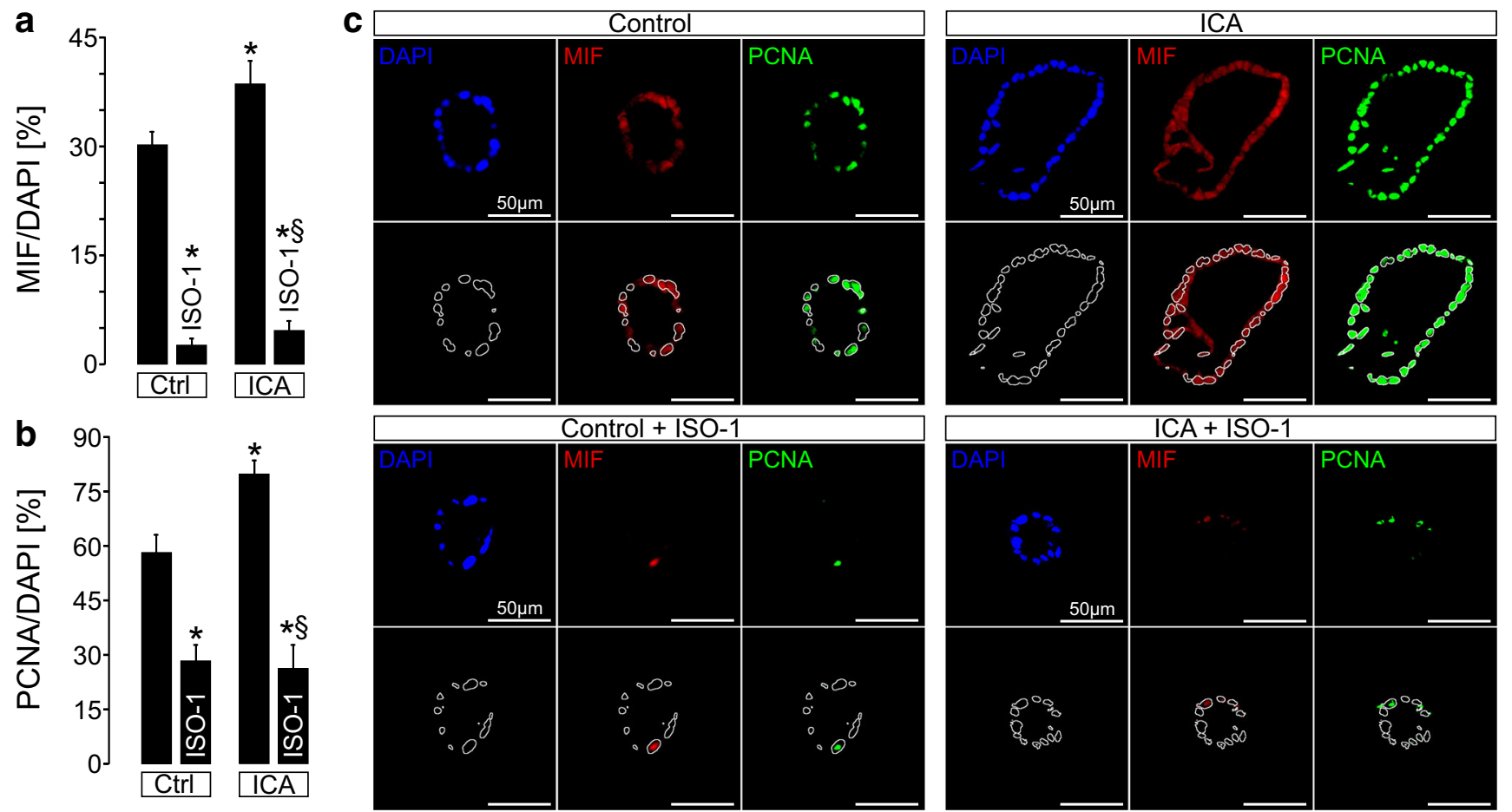

Fig. 6 Inhibition of MIF results in reduction of in vitro cyst cell proliferation. plMDCK cells forming cysts were exposed to control medium containing forskolin $(10 \mu \mathrm{M}) \pm$ application of the MIFinhibitor ISO-1 $(10 \mu \mathrm{M})$ and \pm application of ICA $(10 \mu \mathrm{M})$ for 5 days. a Quantification of MIF-positive cells in the cysts normalized to total cyst cell number obtained by DAPI staining. b Quantification of PCNApositive cells in the cysts normalized to total cyst cell number obtained

GSM2698834 for HIF-1 $\beta$ ) $[32,52]$ and visualized using the USCS Genome browser (https://genome.ucsc.edu/). For chromatin immunoprecipitation, we used HIF-1 $\alpha$ antibodies (6 $\mu$ l; Cay10006421, Cayman Chemicals, Ann Arbor, MI) and HIF-1 $\beta$ antibodies $(6 \mu 1$; NB100-110, Novus Biologicals).

\section{Primary renal tubular cells}

Healthy human kidney cortical tissue from patients undergoing tumor nephrectomy was used for isolation of tubular cells. Informed consent was given by each patient, and the use of the tissue was approved by the local ethical committee at the University of Erlangen-Nuernberg (Approval numbers: 3755 and 173_15Bc). Cells were isolated, cultured and exposed to $1 \mathrm{mM}$ dimethyloxalylglycine (DMOG, Cayman Chemical, Ann Arbor, MI, USA) for $16 \mathrm{~h}$ to stabilize HIF according to the protocol published by Grampp et al. [32].

\section{siRNA transfection and RNA quantification}

siRNA targeting HIF- $1 \alpha$ was conducted as described previously [53]; siRNA against HIF-1 $\beta$ was purchased from Dharmacon (\#L-007207-00-0005; Lafayette, CO, USA). For by DAPI staining. a, b Means of three individual experiments comprising the analysis of $120-130$ cysts per condition. $\mathbf{c}$ Representative stainings of cysts for nuclei (DAPI; blue), MIF (red), and PCNA (green). Outline of nuclei stained by DAPI were marked by a white line to better visualize the proportion of PCNA- and MIF-positive cells and total cell number by overlay (lower rows). *Significant compared with Ctrl. §Significant compared with ICA

primer sequences, see Supplementary Table 1. Transfection and qPCR were performed as described earlier [32]. Briefly, siRNAs at a final concentration of $40 \mathrm{nM}$ were transfected using Saint red (Synvolux, Leiden, The Netherlands) transfection reagent. Transfection was repeated after $24 \mathrm{~h}$, and cells were harvested $48 \mathrm{~h}$ after the initial transfection. RNA from cells or tissue was isolated using Tri Reagent (Sigma-Aldrich) or peqGold total RNA kit (PeqLab, Erlangen, Germany) according to the manufacturer's protocol and transcribed into cDNA using the high capacity cDNA reverse transcription kit (Life Technologies, Carlsbad, CA, USA). qPCRs were performed on a StepOnePlus real-time PCR system (Applied Biosystems, Foster City, CA, USA).

\section{Animal experiments}

All animal experiments were ethically approved by local government authorities and conformed to the US National Institutes of Health Guide for the Care and Use of Laboratory Animals. In this study, kidney sections of a tamoxifen-inducible kidney epithelium-specific Pkd1 deletion mouse model crossed with a HIF- $1 \alpha$ knock-out murine model were used. Generation of the tamoxifen-inducible, kidney epithelium-specific $P k d 1$-deletion mouse model carrying the 
loxP-flanked conditional alleles of $P k d l$ $\left(\mathrm{KspCreER}{ }^{\mathrm{T} 2} ; P k d 1^{\text {lox;lox }}\right)$ has been described previously [54]. Upon administration of tamoxifen to the mice, a genomic fragment containing exons $2-11$ of the Pkd1 gene is specifically deleted in renal epithelial cells inducing cyst formation [54]. $\mathrm{KspCreER}^{\mathrm{T} 2} ; P k d 1^{\text {lox;lox }}$ mice were crossed with mice carrying loxP-flanked alleles of HIF- $1 \alpha\left(H i f-1 \alpha^{\mathrm{fl} ; \mathrm{fl}}\right)$ as described previously in order to receive tamoxifen-inducible, kidney epithelium-specific deletion of $P k d 1$ and Hif- $1 \alpha$ (KspCreER ${ }^{\mathrm{T} 2} P k d 1^{\text {lox;lox }} ;$ Hif-1 $1 \alpha^{\text {lox;lox }}$ [15]. Genotyping was carried out by PCR on tail DNA samples. For genotyping primers, see Supplementary Table 2. Gene deletion was induced by daily intraperitoneal administration of tamoxifen ( $2 \mathrm{mg} / \mathrm{kg}$ body weight) dissolved in 5\% ethanol and 95\% neutral oil from postnatal days (PN) 35-37 to induce a slow disease progression in male mice. $\mathrm{KspCreER}^{\mathrm{T} 2} ; P k d 1^{\text {lox;lox }}$ mice that received vehicle only (without tamoxifen) at the same time points served as controls. PN 35-37 induced $\mathrm{KspCreER} R^{\mathrm{T} 2} ; P k d 1^{1 \mathrm{ox} ; \text { lox }}$ mice (males, $n=7 ;$ ) and $\mathrm{KspCreER}^{\mathrm{T} 2} ; P k d 1^{\text {lox;lox }} ;$ Hif- $1 \alpha^{\text {lox;lox }}$ mice (male: $n=5$ ) received ICA by intraperitoneal injection $(40 \mathrm{mg} / \mathrm{kg}$ body weight; dissolved in 5\% DMSO and 95\% 0.5 M Tris) 5 days per week for 12 weeks and were compared with $\mathrm{KspCreER}{ }^{\mathrm{T} 2} ; P k d 1^{\mathrm{lox} ; 1 \mathrm{ox}}$ mice $(\mathrm{males}, \mathrm{n}=6)$ and $\mathrm{KspCreER}{ }^{\mathrm{T} 2} ; P k d 1^{\text {lox;lox }} ; H i f-1 \alpha^{\text {lox;lox }}$ mice (males, $n=6$ ) that received vehicle (with no ICA). Noninduced but vehicletreated $\mathrm{KspCreER}{ }^{\mathrm{T} 2} ; P k d 1^{\text {lox;lox }}$ mice (males, $\left.n=4\right)$ served as controls. All PN 35-37-induced animals were observed for 12 weeks. Thereafter, animals were sacrificed and kidneys were harvested. The mice of which samples were utilized for this study were characterized for their cystic index as well as serum creatinine levels in our previous paper [15].

\section{Immunoblotting}

plMDCK cells were exposed to control medium, medium supplemented with either forskolin (FSK; $10 \mu \mathrm{M}$ ) or ICA $(10 \mu \mathrm{M})$, or the combination of both, or exposed to $5 \% \mathrm{O}_{2}$ for $24 \mathrm{~h}$. Proteins were dissolved in lysis buffer containing $6.65 \mathrm{M}$ urea, $10 \%$ glycerol, $10 \mathrm{mM}$ Tris- $\mathrm{HCl}(\mathrm{pH} 6.8), 1 \%$ SDS, $5 \mathrm{mM}$ dithiothreitol, and complete protease inhibitors (Roche) and sonicated. Fifty micrograms of proteins were used for immunodetection of MIF. Proteins were detected with the primary polyclonal rabbit anti MIF antibody (1:1000; Sigma-Aldrich, Missouri, USA). As secondary antibody, a polyclonal goat antirabbit (1:10000, Dako, Hamburg, Germany) antibody was used. For detection of HIF-1 $\alpha$ and HIF- $1 \beta, 50 \mu \mathrm{g}$ of primary renal tubular cells were used. Proteins were detected with the primary polyclonal rabbit antiHIF- $1 \alpha$ antibody (1:1000; Cay 10006421 , Cayman Chemicals, Ann Arbor, MI) and polyclonal rabbit antiHIF$1 \beta$ antibody (1:1000; NB100-110, Novus Biologicals). As secondary antibodies, an antirabbit IgG (1:500; Vector,
Burlingame, CA) was used. Beta actin was detected with a HRP-coupled rabbit antibody (1:30000, Sigma Aldrich).

\section{Immunofluorescence, immunohistochemistry, and antibodies}

plMDCK cysts at day 5 were rinsed in phosphate-buffered saline (PBS) supplemented with $0.9 \mathrm{mmol} / \mathrm{l}$ calcium chloride and $0.49 \mathrm{mmol} / \mathrm{l}$ magnesium chloride (PBS+). Paraformaldehyde (4\%) was added to fix the cysts for $1 \mathrm{~h}$ at room temperature. Glycine $(200 \mathrm{mmol} / \mathrm{l})$ in PBS+ was added for another hour to quench the excess aldehyde. Three-micrometer paraffin sections were costained for MIF and PCNA. Sections were boiled for $7 \mathrm{~min}$ in a steam pressure pot $\left(120^{\circ} \mathrm{C}\right)$ in a modified citrate buffer (Target Retrieval Solution; S1699, Agilent, Waldbronn, Germany). Blocking was performed using $1 \%$ $\mathrm{BSA} / \mathrm{PBS}^{+}$for $30 \mathrm{~min}$. at room temperature. Primary rabbit MIF- (FI-115, 1:100, Santa Cruz, Heidelberg, Germany) and mouse PCNA antibody (M0879, 1:100, Dako) were incubated overnight. After washing with $\mathrm{PBS}^{+}$, the binding of the primary antibodies were visualized using secondary rabbit Alexa Fluor 555 and mouse Alexa Fluor 488 (1:1000, Thermo Fisher Scientific, Inc., Erlangen, Germany) for $90 \mathrm{~min}$. For detection of MIF in the kidney, three-micron transverse kidney sections, fixed overnight in paraformaldehyde (4\%) and embedded in paraffin, were stained. Sections were deparaffinized and were boiled at $120^{\circ} \mathrm{C}$ in a steam pressure pot for $6.5 \mathrm{~min}$. Sections were exposed to $3 \%$ peroxidase for $10 \mathrm{~min}$ before incubation in horse serum (ImmPRESS horse antirabbit IgG Polymer kit, Vector, Burlingame, CA) for 20 min. Primary rabbit MIF antibody (FI-115, 1:100) was incubated at $4{ }^{\circ} \mathrm{C}$ overnight. Thereafter, the sections were washed in Tris-buffered saline with Tween20 (TBST) and treated with rabbit ImPess Kit (30 min, MP-7401, Vector). Visualization of the MIF signal was performed using Diaminobenzidin (K1500 from CSA kit, Dako). For detection of ABCA1, kidney sections were boiled in a steam pressure pot at $120{ }^{\circ} \mathrm{C}$ in Target Retrieval Solution for $5 \mathrm{~min}$. After washing in TBST the sections were blocked using AVIDIN/ BIOTIN Blocking kit (P2001, Vector, Burlingame, CA, USA) for $20 \mathrm{~min}$. before adding $3 \%$ peroxidase for $10 \mathrm{~min}$. Sections were incubated in protein block serum free (X0909, Dako) for 60 min. Primary antibody rabbit IgG polyclonal ABCA1 (1:500, Thermo Fisher Scientific, Inc.) was incubated at $4{ }^{\circ} \mathrm{C}$ overnight. After washing with TBST the ABCA1 signal was detected using a secondary goat biotinylated IgG antibody (1:500, Vector) for $30 \mathrm{~min}$. at room temperature. Thereafter, a Vectastain ABC-Komplex (Vector PK-6100, 15 min.) was added. In a further step Biotin Plus Amplification Reagent TSA Plus Biotin Kit (1:50, PerkinElmer, Hamburg, Germany) for $15 \mathrm{~min}$. was added. Finally, an incubation step in Streptavidin (Dako) was added for $30 \mathrm{~min}$. Visual detection of the signal was performed using 
a chromogen detection solution Diaminobenzidin (K1500 from CSA kit, Dako) plus substrate buffer concentrate (K1500 from CSA kit, Dako). A hematoxylin by Gill (Merck, Darmstadt, Germany) counterstaining was performed in addition. For detection of HIF- $1 \alpha$, polyclonal rabbit antiHIF-1 $\alpha$ (1:5000; Cayman Chemicals, Ann Arbor, MI) primary antibody was used. Thereafter, a catalyzed signal amplification system and a biotinylated secondary antirabbit IgG (1:500; Vector, Burlingame, CA) were used. Dolichos biflorus agglutinin (DBA) was visualized using fluoresceinlabeled DBA (Vector Laboratories) to identify collecting ducts. Proximal tubules were detected by their characteristic brush borders and green autofluorescence. Signals were captured with a DM6000B fluorescence microscope (Leica, Wetzlar, Germany), and photographs were taken with a Leica DFC 450C camera.

\section{Quantification of MIF and ABCA1 staining}

Eight random photographs were taken from the cortex and medulla of each kidney (Ctrl: $n=5 ; P k d 1^{\mathrm{fl} ; \mathrm{fl}:} n=6$; $P k d 1^{\mathrm{fl} ; \mathrm{fl}} ; H i f-1 \alpha^{\mathrm{fl} ; \mathrm{fl}}: n=6 ; P k d 1^{\mathrm{fl} ; \mathrm{fl}}+\mathrm{ICA}: n=7 ; P k d 1^{\mathrm{fl} ; \mathrm{fl}} ; H i f-$ $1 \alpha^{\mathrm{fl} ; \mathrm{fl}}+\mathrm{ICA}: n=5$ ) at a magnification of $\times 200$. Immunohistochemical signals of MIF and ABCA1 were analyzed as described previously [15]. Briefly, a color deconvolution algorithm (ImageJ software version 1.48) was applied to dissect the different signals and turned into 8-bit Lookup Table (LUT) images, followed by binarization and particle analysis to obtain the ratio of positive area per total cortex or medullary area. Fluorescent signals were analyzed and normalized as described previously [55].

\section{Analysis of subcellular localization of MIF}

A total of $n=337$ tubular segments or cysts from $n=3$ individual $\mathrm{KspCreER}{ }^{\mathrm{T} 2} ; P k d 1^{\text {lox;lox }}$ mouse kidneys stained for MIF were separated into normal tubules defined by a luminal diameter $<50 \mu \mathrm{m}$, dilated tubules defined by diameters between 50 and $100 \mu \mathrm{m}$ and cysts defined by diameters $>$ $100 \mu \mathrm{m}$ by the use of ImageJ (V. 1.48) and analyzed for either cytoplasmic MIF staining patterns (no signal in nucleus) or nuclear staining patterns (apparent nuclear signal).

\section{Cell proliferation assays}

Two assays were performed to analyze cell proliferation. First, a CellTiter 96 Aqueous One Solution Cell Proliferation Assay (G3582, Promega), also known as classical MTS assay, was performed according to the manufacturer's protocol. Cells were seeded (1250 cells/well) in a 96-well plate in the presence or absence of 10 and $100 \mu \mathrm{M}$ ISO- 1 or 10 and $100 \mathrm{ng} / \mathrm{ml}$ recombinant MIF (rMIF), respectively. After 47 hours, CellTiter 96 Aqueous One Solution Reagent was added to each well and absorbance was measured after $1 \mathrm{~h}$ of incubation time. Second, the RealTime-Glo MT Cell Viablility Assay (G9711, Promega) was performed according to the manufacturer's protocol. Cells were seeded into 96-well plates (1250 cells/well) in control medium. Twenty-four hours later, medium was changed and supplemented with Cell Viability Substrate, NanoLuc Enzyme, and 0, 10, and $100 \mu \mathrm{M}$ ISO-1 or 0,10 , and $100 \mathrm{ng} / \mathrm{ml}$ recombinant MIF (rMIF), respectively. Twenty-four hours later, luminescence was measured with an integration time of $0.5 \mathrm{~s}$ which served as starting point. Ten hours later, luminescence was measured again, and the delta increase in the obtained values was analyzed.

\section{TUNEL assay}

Terminal deoxynucleotidyl transferase dUTP nick end labeling (TUNEL) Assays were performed utilizing the Molecular Probes Click-iT Plus TUNEL Assay (C10618, Invitrogen). Paraffin sections of plMDCK cysts were stained according to the manufacturer's protocol.

\section{Quantification of TUNEL- and PCNA signals in pIMDCK cysts}

plMDCK cysts were stained for DAPI, MIF, PCNA, and TUNEL after 5 days of application of control medium containing forskolin $(10 \mu \mathrm{M})$ and supplemented with the MIFinhibitor ISO-1 $(10 \mu \mathrm{M})$ or ICA $(10 \mu \mathrm{M}) . n=120-130$ cysts per condition from three individual experiments were analyzed for MIF, PCNA, and TUNEL-positive cells within the cysts and normalized to total cyst cell number obtained by DAPI staining. Outline of nuclei stained by DAPI were marked by a white line by ImageJ (V.1.48) to better visualize the fraction of PCNA-, MIF-, and TUNEL-positive cells.

\section{Statistical analysis}

Data are expressed as mean \pm SEM. Differences among groups were analyzed using one-way ANOVA, followed by a Bonferroni test for multiple comparisons. An unpaired $t$ test was applied to compare the differences between two groups. Wilcoxon signed-rank test for columns statistics was used for relative values. $P<0.05$ was considered statistically significant.

Acknowledgments Open Access funding provided by Projekt DEAL. We thank Barbara Teschemacher and Eugenia Schefler for their excellent technical support. BB and JS were supported by the Deutsche Forschungsgemeinschaft (DFG, German Research Foundation), project number 387509280, SFB 1350, projects A2, B3 and C5, respectively). AK, SG and WS were supported by the Interdisciplinary Center for Clinical Research Erlangen (junior projects J71, J64 and laboratory rotation, respectively). 
Authors' contributions WS, AK, BB have designed studies, conducted experiments, acquired and analyzed data, and have written the manuscript. SG has conducted experiments, acquired and analyzed data. JS has designed studies and analyzed data.

\section{Compliance with ethical standards}

Conflict of interest The authors declare that they have no conflict of interest.

Open Access This article is licensed under a Creative Commons Attribution 4.0 International License, which permits use, sharing, adaptation, distribution and reproduction in any medium or format, as long as you give appropriate credit to the original author(s) and the source, provide a link to the Creative Commons licence, and indicate if changes were made. The images or other third party material in this article are included in the article's Creative Commons licence, unless indicated otherwise in a credit line to the material. If material is not included in the article's Creative Commons licence and your intended use is not permitted by statutory regulation or exceeds the permitted use, you will need to obtain permission directly from the copyright holder. To view a copy of this licence, visit http://creativecommons.org/licenses/by/4.0/.

\section{References}

1. Harris PC, Torres VE (2014) Genetic mechanisms and signaling pathways in autosomal dominant polycystic kidney disease. J Clin Invest 124:2315-2324

2. Grantham JJ, Mulamalla S, Swenson-Fields KI (2011) Why kidneys fail in autosomal dominant polycystic kidney disease. Nat Rev Nephrol 7:556-566

3. Chebib FT, Sussman CR, Wang X et al (2015) Vasopressin and disruption of calcium signalling in polycystic kidney disease. Nat Rev Nephrol 11:451-464

4. Terryn S, Ho A, Beauwens R, Devuyst O (2011) Fluid transport and cystogenesis in autosomal dominant polycystic kidney disease. Biochim Biophys Acta 1812:1314-1321

5. Song CJ, Zimmerman KA, Henke SJ, Yoder BK (2017) Inflammation and fibrosis in polycystic kidney disease. In: Miller RK (ed) Kidney Development and Disease. Springer International Publishing, Cham, pp 323-344

6. Xue C, Mei C-L (2019) Polycystic kidney disease and renal fibrosis. Adv Exp Med Biol 1165:81-100

7. Karihaloo A, Koraishy F, Huen SC et al (2011) Macrophages promote cyst growth in polycystic kidney disease. J Am Soc Nephrol 22:1809-1814

8. Swenson-Fields KI, Vivian CJ, Salah SM et al (2013) Macrophages promote polycystic kidney disease progression. Kidney Int 83:855864

9. Chen L, Zhou X, Fan LX et al (2015) Macrophage migration inhibitory factor promotes cyst growth in polycystic kidney disease. $\mathrm{J}$ Clin Invest 125:2399-2412

10. Calandra T, Roger T (2003) Macrophage migration inhibitory factor: a regulator of innate immunity. Nat Rev Immunol 3:791-800

11. Du W, Wright BM, Li X et al (2013) Tumor-derived macrophage migration inhibitory factor promotes an autocrine loop that enhances renal cell carcinoma. Oncogene 32:1469-1474

12. Choudhary S, Hegde P, Pruitt JR et al (2013) Macrophage migratory inhibitory factor promotes bladder cancer progression via increasing proliferation and angiogenesis. Carcinogenesis 34:28912899
13. Bernhardt WM, Wiesener MS, Weidemann A et al (2007) Involvement of hypoxia-inducible transcription factors in polycystic kidney disease. Am J Pathol 170:830-842

14. Buchholz B, Schley G, Faria D et al (2014) Hypoxia-inducible factor-1alpha causes renal cyst expansion through calciumactivated chloride secretion. J Am Soc Nephrol 25:465-474

15. Kraus A, Peters DJM, Klanke B, et al (2018) HIF- $1 \alpha$ promotes cyst progression in a mouse model of autosomal dominant polycystic kidney disease. Kidney Int 0: https://doi.org/10.1016/j.kint.2018. 06.008

16. Semenza GL (2011) Oxygen sensing, homeostasis, and disease. N Engl J Med 365:537-547

17. Schödel J, Ratcliffe PJ (2019) Mechanisms of hypoxia signalling: new implications for nephrology. Nat Rev Nephrol 15:641-659

18. Chen N, Hao C, Liu B-C et al (2019) Roxadustat treatment for anemia in patients undergoing long-term dialysis. N Engl J Med 381:1011-1022

19. Chen N, Hao C, Peng X et al (2019) Roxadustat for anemia in patients with kidney disease not receiving dialysis. N Engl J Med 381:1001-1010

20. Buchholz B, Eckardt K-U (2020) Role of oxygen and the HIFpathway. Cell Signal 109524. https://doi.org/10.1016/j.cellsig. 2020.109524

21. Koong AC, Denko NC, Hudson KM et al (2000) Candidate genes for the hypoxic tumor phenotype. Cancer Res 60:883-887

22. Bacher M, Schrader J, Thompson N et al (2003) Up-regulation of macrophage migration inhibitory factor gene and protein expression in glial tumor cells during hypoxic and hypoglycemic stress indicates a critical role for angiogenesis in glioblastoma multiforme. Am J Pathol 162:11-17

23. Heim C, Motsch B, Jalilova S et al (2016) Reduction of obliterative bronchiolitis $(\mathrm{OB})$ by prolyl-hydroxylase-inhibitors activating hypoxia-inducible transcription factors in an experimental mouse model. Transpl Immunol 39:66-73

24. Ortiz-Barahona A, Villar D, Pescador N et al (2010) Genome-wide identification of hypoxia-inducible factor binding sites and target genes by a probabilistic model integrating transcription-profiling data and in silico binding site prediction. Nucleic Acids Res 38: 2332-2345

25. Parekh A, Das S, Parida S et al (2018) Multi-nucleated cells use ROS to induce breast cancer chemo-resistance in vitro and in vivo. Oncogene 37:4546-4561

26. Baugh JA, Gantier M, Li L et al (2006) Dual regulation of macrophage migration inhibitory factor (MIF) expression in hypoxia by CREB and HIF-1. Biochem Biophys Res Commun 347:895-903

27. Tang Y, Wan W, Wang L et al (2015) microRNA-451 inhibited cell proliferation, migration and invasion through regulation of MIF in renal cell carcinoma. Int J Clin Exp Pathol 8:15611-15621

28. Flieger O, Engling A, Bucala R et al (2003) Regulated secretion of macrophage migration inhibitory factor is mediated by a nonclassical pathway involving an $\mathrm{ABC}$ transporter. FEBS Lett 551: $78-86$

29. Schley G, Klanke B, Schodel J et al (2012) Selective stabilization of HIF-1alpha in renal tubular cells by 2-oxoglutarate analogues. Am J Pathol 181:1595-1606

30. Hofherr A, Busch T, Köttgen M (2018) HIF-1 $\alpha$ drives cyst growth in advanced stages of autosomal dominant polycystic kidney disease. Kidney Int 94:849-851

31. Keller C, Kroening S, Zuehlke J et al (2012) Distinct mesenchymal alterations in $\mathrm{N}$-cadherin and $\mathrm{E}$-cadherin positive primary renal epithelial cells. PLoS One 7:e43584

32. Grampp S, Schmid V, Salama R et al (2017) Multiple renal cancer susceptibility polymorphisms modulate the HIF pathway. PLoS Genet 13:e1006872

33. Buchholz B, Teschemacher B, Schley G et al (2011) Formation of cysts by principal-like MDCK cells depends on the synergy of 
cAMP- and ATP-mediated fluid secretion. J Mol Med Berl 89:251261

34. Raphael KL, Strait KA, Stricklett PK et al (2009) Inactivation of Pkd1 in principal cells causes a more severe cystic kidney disease than in intercalated cells. Kidney Int 75:626-633

35. Kraus A, Grampp S, Goppelt-Struebe M et al (2016) P2Y2R is a direct target of HIF-1alpha and mediates secretion-dependent cyst growth of renal cyst-forming epithelial cells. Purinergic Signal 12: 687-695

36. Kraus A, Schley G, Kunzelmann K et al (2016) Glucose promotes secretion-dependent renal cyst growth. J Mol Med Berl 94:107-117

37. Buchholz B, Faria D, Schley G et al (2014) Anoctamin 1 induces calcium-activated chloride secretion and proliferation of renal cystforming epithelial cells. Kidney Int 85:1058-1067

38. Tao Y, Kim J, Faubel S et al (2005) Caspase inhibition reduces tubular apoptosis and proliferation and slows disease progression in polycystic kidney disease. Proc Natl Acad Sci U A 102:6954 6959

39. Serra AL, Poster D, Kistler AD et al (2010) Sirolimus and kidney growth in autosomal dominant polycystic kidney disease. $\mathrm{N}$ Engl J Med 363:820-829

40. Torres VE, Chapman AB, Devuyst O et al (2012) Tolvaptan in patients with autosomal dominant polycystic kidney disease. N Engl J Med 367:2407-2418

41. Walz G, Budde K, Mannaa M et al (2010) Everolimus in patients with autosomal dominant polycystic kidney disease. N Engl J Med 363:830-840

42. Fu H, Luo F, Yang L et al (2010) Hypoxia stimulates the expression of macrophage migration inhibitory factor in human vascular smooth muscle cells via HIF-1alpha dependent pathway. BMC Cell Biol 11:66

43. Hahne M, Schumann P, Mursell M et al (2018) Unraveling the role of hypoxia-inducible factor (HIF)- $1 \alpha$ and HIF- $2 \alpha$ in the adaption process of human microvascular endothelial cells (HMEC-1) to hypoxia: Redundant HIF-dependent regulation of macrophage migration inhibitory factor. Microvasc Res 116:34-44

44. Roger T, Ding X, Chanson A-L et al (2007) Regulation of constitutive and microbial pathogen-induced human macrophage migration inhibitory factor (MIF) gene expression. Eur J Immunol 37: 3509-3521
45. Li J, Tang Y, Tang PMK et al (2018) Blocking macrophage migration inhibitory factor protects against cisplatin-induced acute kidney injury in mice. Mol Ther 26:2523-2532

46. Zhou JX, Li X (2015) Apoptosis in polycystic kidney disease: from pathogenesis to treatment. In: Li X (ed) Polycystic Kidney Disease. Codon Publications, Brisbane (AU)

47. Schley G, Klanke B, Kalucka J et al (2019) Mononuclear phagocytes orchestrate prolyl hydroxylase inhibition-mediated renoprotection in chronic tubulointerstitial nephritis. Kidney Int 96:378-396

48. Dell KM, Nemo R, Sweeney WE et al (2001) A novel inhibitor of tumor necrosis factor-alpha converting enzyme ameliorates polycystic kidney disease. Kidney Int 60:1240-1248

49. Li X, Magenheimer BS, Xia S et al (2008) A tumor necrosis factoralpha-mediated pathway promoting autosomal dominant polycystic kidney disease. Nat Med 14:863-868

50. Buchholz B, Klanke B, Schley G et al (2011) The Raf kinase inhibitor PLX5568 slows cyst proliferation in rat polycystic kidney disease but promotes renal and hepatic fibrosis. Nephrol Dial Transpl 26:3458-3465

51. Gekle M, Wünsch S, Oberleithner H, Silbernagl S (1994) Characterization of two MDCK-cell subtypes as a model system to study principal cell and intercalated cell properties. Pflügers Arch Eur J Physiol 428:157-162

52. Grampp S, Platt JL, Lauer V et al (2016) Genetic variation at the 8q24.21 renal cancer susceptibility locus affects HIF binding to a MYC enhancer. Nat Commun 7:13183

53. Elvidge GP, Glenny L, Appelhoff RJ et al (2006) Concordant regulation of gene expression by hypoxia and 2-oxoglutaratedependent dioxygenase inhibition: the role of HIF-1alpha, HIF-2alpha, and other pathways. J Biol Chem 281:15215-15226

54. Lantinga-van Leeuwen IS, Leonhard WN, van de Wal A et al (2006) Transgenic mice expressing tamoxifen-inducible Cre for somatic gene modification in renal epithelial cells. Genesis 44: $225-232$

55. Schley G, Scholz H, Kraus A et al (2015) Hypoxia inhibits nephrogenesis through paracrine Vegfa despite the ability to enhance tubulogenesis. Kidney Int 88:1283-1292

Publisher's note Springer Nature remains neutral with regard to jurisdictional claims in published maps and institutional affiliations. 